\title{
Catalytic performance and deactivation of sulfonated hydrothermal carbon in the esterification of fatty acids. Comparison with sulfonic solids of different nature.
}

José M. Fraile, ${ }^{* a}$ Enrique García-Bordejé, ${ }^{b}$ Elísabet Pires, ${ }^{a}$ and Laura Roldán ${ }^{\mathrm{b}}$

${ }^{a}$ Instituto de Sintesis Química y Catálisis Homogénea (ISQCH), Facultad de Ciencias, C.S.I.C. - Universidad de Zaragoza, E-50009 Zaragoza, Spain. E-mail:

jmfraile@unizar.es

${ }^{b}$ Instituto de Carboquimica (ICB-CSIC), Miguel Luesma Castán 4, E-50018 Zaragoza, Spain

\begin{abstract}
Sulfonated hydrothermal carbon is able to catalyze the esterification of palmitic acid with methanol with higher initial rate per site than other well-known sulfonic solids, including stronger acids such as nafion-silica. Although the origin of this higher rate per site is not clear, it seems to be related with a high surface density of acid groups (both carboxylic and sulfonic). At the same time, their close proximity makes it possible the mutual activation of the surface groups for esterification with methanol. The formation of sulfonate esters on the surface produces the irreversible partial deactivation of the solid for a second reaction. Other solids able to bring sulfonic groups close, such as Dowex, show the same deactivation pattern but their sites are less active than those in the sulfonated hydrothermal carbon. As an additional advantage, this solid displays an enhanced stability against the presence of water, which enables the improvement of the behavior after recovery by minimizing the esterification of the surface acid sites.
\end{abstract}

Keywords: sulfonated hydrothermal carbon; sulfonic solids; esterification; deactivation; acid catalysts 


\section{Introduction}

Acidic solids are among the most useful heterogeneous catalysts, for both bulk [1,2] and fine chemicals [3] synthesis. Sulfonic acids supported on inert matrixes have been envisaged as interesting alternatives to classical inorganic acid solids. Polystyrene supported sulfonic acids are commonly applied as catalysts [4], even in industrial processes, but new developments are still being produced to optimize their performance $[5,6]$. Perfluorinated sulfonic polymers constitute a special type of solids with enhanced acidity [7]. The development of sulfonic organic-inorganic hybrid materials tried to overcome the possible problems of lack of thermal and mechanical resistance of the polymeric materials. Propylsulfonic and arylsulfonic groups have been incorporated on amorphous silica [8] and more recently on siliceous mesostructured materials $[9,10]$, whereas nafion-silica nanocomposites have been developed by entrapment of nafion chains into the silica structure [11]. One alternative to both organic and hybrid materials is the family of sulfonated carbons [12].

Esterification of carboxylic acids is an important industrial acid-catalyzed reaction [13], and one example is the synthesis of fatty acid methyl esters [14]. All the types of sulfonic heterogeneous catalysts have been used for this kind of reaction, including sulfonated polystyrene [5,15], organosulfonic mesoporous silicas [16,17], nafion-silica nanocomposite [18], and sulfonated carbons prepared by thermal [19] or hydrothermal carbonization [20], as well as ordered mesoporous carbon [21]. Our group has described the esterification of palmitic acid with methanol catalyzed by a sulfonated hydrothermal carbon prepared from glucose, either in bulk [22] or supported on graphite felt [23].

In the literature, generally the performance of catalysts of similar nature are compared, whereas the comparisons of sulfonic solids of different nature are scarce and not directly related to esterification reactions [24,25]. Additionally, the question of deactivation of solid acids is of great interest in connection with their practical application. Whereas some authors have described an almost full recovery of sulfonic acids after esterification reactions $[19,26]$, in other cases partial deactivation has been observed. This has been attributed to different causes, such as leaching of sulfonated material [27], or pore blocking with fatty acid derivatives $[18,28]$. In our previous work, [22] the deactivation of sulfonated hydrothermal carbon by methanol was described as a consequence of methyl sulfonyl ester formation. 
The objective of the present work is to compare the catalytic performance of sulfonic solids of different nature in the esterification of fatty acids, taking palmitic acid as a model, as well as their behavior with respect to deactivation with methanol, and to correlate both aspects with the properties of the solids.

\section{Experimental section}

\subsection{Materials}

Dowex 50W $\times 2(\mathrm{D} 50$, sulfonated polystyrene gel-type resin, 2\% divinylbenzene, 50-100 mesh) and Dowex CCR-2 (CCR, carboxylic polyacrylic gel-type resin, 20-50 mesh) were purchased from Fluka. Amberlyst 15 (A15, sulfonated polystyrene macroreticular resin, 20\% divinylbenzene) was purchased from Alfa Aesar. Propylsulfonic silica (PSS, $\approx 0.74 \mathrm{mmol} / \mathrm{g}$ loading) was purchased from Aldrich. Deloxan ASP I/9 (DI9, 0.1-0.4 $\mathrm{mm}$ particle size) was a gift from Degussa. SAC-13 (nafion-silica composite, 13\% wt nafion content) was a gift from Dupont. All the solids were dried at $120^{\circ} \mathrm{C}$ overnight prior to use as catalysts. Norit SX Ultra Cat 8020-1 and Elorit 8042-1 were a gift from CABOT.

\subsection{Preparation of sulfonic carbons}

Sulfonated hydrothermal carbon (SHTC). The solid was prepared from glucose in two steps, hydrothermal synthesis in water and sulfonation with concentrated sulfuric acid, as previously described [22].

Sulfonated carbon nanofibers (SCNF). For the growth of carbon nanofibers (CNF), a catalyst with $20 \% \mathrm{Ni}$ was prepared by incipient wetness impregnation on $\gamma$-alumina (Pural, Sasol). After calcination in $\mathrm{N}_{2}$ for two hours at $600{ }^{\circ} \mathrm{C}$, heating rate $1{ }^{\circ} \mathrm{C} / \mathrm{min}$, and reduction in $\mathrm{H}_{2}$ for 1 hour at $550^{\circ} \mathrm{C}$ in a quartz reactor, the carbon nanofiber growth was carried out by hydrocarbon decomposition. To this end, a gas mixture of $\mathrm{C}_{2} \mathrm{H}_{6}: \mathrm{H}_{2}$ 50:50 (v/v) was fed to the reactor containing the growth catalyst at $600^{\circ} \mathrm{C}$ during 3 hours. After the $\mathrm{CNF}$ growth, the catalyst was removed by purification first with $\mathrm{NaOH}$ $(5 \mathrm{M})$ at $80^{\circ} \mathrm{C}$ and subsequently with concentrated $\mathrm{HNO}_{3}(65 \%)$ at $80{ }^{\circ} \mathrm{C}$. The thermogravimetric oxidation of the solid up to $700^{\circ} \mathrm{C}$ shows less than $2 \mathrm{wt} \%$ of residue. Sulfonation was carried out under the same conditions used for hydrothermal carbon. 
Sulfonated activated carbons (SNor and SElor). Norit SX Ultra Cat 8020-1 and Elorit 8042-1 were sulfonated under the same conditions (concentrated sulfuric acid, $150^{\circ} \mathrm{C}$, $15 \mathrm{~h}$ ) as the other carbons to give SNor and SElor, respectively.

\subsection{Characterization}

Surface areas were determined by $\mathrm{N}_{2}$ adsorption (BET) using a Micromeritics ASAP 2020 apparatus, after outgassing for $4 \mathrm{~h}$ at $423 \mathrm{~K}$. C,H,S elemental analyses were carried out by combustion in a ThermoFlash 1112 elemental analyzer equipped with a TCD detector. Oxygen analysis was performed by direct assay, which involves pyrolysis of the sample at $1070{ }^{\circ} \mathrm{C}$ in a nickel/carbon bed under a controlled He flow. The outlet flow, after passing a separation column, ends in a TCD detector. The oxygen content of the sample is quantified on the basis of the amount of CO analyzed. IR spectrum was recorded with a Nicolet Avatar 360 spectrometer.

The total amount of acid sites on each catalyst was determined by back titration. The solid (30-100 mg depending on the catalyst acidity) was added to $25 \mathrm{~mL}$ of $0.01 \mathrm{M}$ $\mathrm{NaOH}$ solution $(0.0025 \mathrm{M}$ in the cases of SAC-13 and sulfonated carbon nanofibers) and allowed to equilibrate under stirring for $1 \mathrm{~h}$. Thereafter, it was titrated with $0.05 \mathrm{M}$ potassium hydrogen phthalate solution $(0.01 \mathrm{M}$ in the cases of SAC-13 and sulfonated carbon nanofibers) using a Crison $\mathrm{pH}$ Burette 24.

MAS NMR spectra were recorded in a Bruker Avance III WB400 spectrometer with 4 $\mathrm{mm}$ zirconia rotors spun at magic angle in $\mathrm{N}_{2}$ at $10 \mathrm{kHz}(12 \mathrm{kHz}$ in the case of D50, A15 and CCR). ${ }^{1} \mathrm{H}^{13}{ }^{13} \mathrm{CP}$ spectra (up to 10000 scans) were measured using a ${ }^{1} \mathrm{H} \pi / 2$ pulse length of $2.45 \mu \mathrm{s}$, with a contact time of $2 \mathrm{~ms}$, and spinal64 proton decoupling sequence of $4.6 \mu$ s pulse length. ${ }^{31} \mathrm{P}$ NMR spectra of adsorbed triethylphosphine oxide (TEPO) were recorded using a ${ }^{31} \mathrm{P} \pi / 2$ pulse length of $4.3 \mu$ s without proton decoupling, with 30 s recycle delay.

Ex-situ XPS spectra were recorded with an AXIS ultra DLD of Kratos Analytical Limited system equipped with $\mathrm{Al} \mathrm{K} \alpha$ radiation source to excite the sample. Calibration of the instrument was done with $\mathrm{Ag} 3 \mathrm{~d}_{5 / 2}$ line at $368.27 \mathrm{eV}$. All measurements were performed under UHV, better than $10^{-10}$ Torr. Internal referencing of spectrometer energies was made using the dominating $\mathrm{C} 1 \mathrm{~s}$ peak of the carbon catalyst at $284.6 \mathrm{eV}$. 
The program used to do curve fitting of the spectra was CasaXPS after Shirley baseline method.

\subsection{Catalytic tests.}

$7.5 \mathrm{mmol}$ of palmitic acid (1.92 g), $75.0 \mathrm{mmol}$ of methanol $(3.04 \mathrm{ml})$, the catalyst (10 $\mathrm{mg}$ of D50; $100 \mathrm{mg}$ of A15, DI9, PSS, HTC, SHTC; $200 \mathrm{mg}$ of SAC-13; $300 \mathrm{mg}$ of SCNF, CCR, SNor and SElor) and $2.1 \mathrm{mmol}$ of 1-methylnaphthalene (0.30 g) as internal standard were stirred $(\approx 1000 \mathrm{rpm})$ in a round flask immersed into a silicone bath at $85^{\circ} \mathrm{C}$. Reaction was monitored by gas chromatography (HP-5890-II). The catalyst was filtered, washed with $\mathrm{CH}_{2} \mathrm{Cl}_{2}$ and a small amount of methanol, dried under vacuum, and reused under the same conditions.

The kinetic studies were carried out in $7.5 \mathrm{ml}$ scale in $25 \mathrm{ml}$ round-bottom flasks immersed in silicone baths at $85^{\circ} \mathrm{C}$. The reactions were started by addition of the required amount of methanol on the pre-heated mixture of catalyst, internal standard, palmitic acid and dioxane, to prevent the possible deactivation of the catalyst in the presence of methanol. In that way, the volume of dioxane was calculated by considering $\mathrm{V}_{\mathrm{MeOH}}+\mathrm{V}_{\text {dioxane }}+\mathrm{V}_{\text {palmitic }}+\mathrm{V}_{1-\text { methylnaphthalene }}=7.5 \mathrm{ml}$, as the possible error was less important than that produced in the other possible alternatives (starting the reaction by addition of palmitic acid or catalyst).

\subsection{Deactivation tests.}

The catalyst $(150 \mathrm{mg})$ was stirred under reflux in methanol $(40 \mathrm{ml})$ for $72 \mathrm{~h}$. The solid was filtered at the same temperature and dried under vacuum at $105^{\circ} \mathrm{C}$. In some cases, the catalyst was then thoroughly washed with dichloromethane at room temperature. For NMR characterization some solids were treated for longer times ( $72 \mathrm{~h}$ periods) at $50^{\circ} \mathrm{C}$ under vacuum. The solid was used in esterification of palmitic acid with methanol under the standard conditions.

DI9, SHTC, SElor and D50 were treated with benzyl alcohol. The catalyst (200 mg) was stirred at $100^{\circ} \mathrm{C}$ with benzyl alcohol $(1.4 \mathrm{~mL})$ in toluene $(1.4 \mathrm{ml})$ for $96 \mathrm{~h}$. The solid was filtered at the same temperature, washed with toluene and dried at $120^{\circ} \mathrm{C}$. 


\section{Results and Discussion}

\subsection{Types of catalysts used}

Several sulfonic solids of different nature (Figure 1) were tested in an attempt to compare the performance of groups attached to chains of different chemical nature. SAC-13 nafion-silica nanocomposite [11] was selected as an example of sulfonic groups attached to perfluorinated chains, in principle without the possible diffusion problems of bulk nafion. The acidity of this solid would be analogous to Nafion $\left(\mathrm{H}_{0}\right.$ -11 to -13 [29]). Dowex $50 \mathrm{~W} \times 2$ (D50) was chosen as an example of aromatic sulfonic groups in a polystyrene gel type resin (low cross-linking degree, $2 \%$ divinylbenzene) and Amberlyst 15 (A15) as an analogous macroreticular example (high cross-linking degree, $20 \%$ divinylbenzene), whose $\mathrm{H}_{0}$ has been determined to be -2.2 [29]. Propylsulfonic silica (PSS) [8] and Deloxan ASP I/9 (DI9) [30] were chosen as examples of aliphatic sulfonic groups, whose $\mathrm{H}_{0}$ value has been estimated in -3 in [31].

\section{Figure 1 near here}

With regard to carbons, hydrothermal carbon derived from glucose (HTC) shows a polyfuran structure, connected by aliphatic chains [32]. Sulfonation produces a deep transformation in the chemical nature of the backbone, with a decrease in the amount of aliphatic chains, increase of aromatic rings and presence of oxidized groups [33,34], in addition to sulfonic groups, presumably arylsulfonic ones [33]. For the sake of comparison, sulfonated carbons of graphitic nature were also prepared from Norit and Elorit activated carbons and nanofibers. Carbon nanofibers (CNF) [35] were prepared by catalytic decomposition of ethane over $\mathrm{Ni}$ /alumina catalyst. The formation of nanofibers was confirmed by TEM (Figure 2). Sulfonation of this kind of materials has been scarcely described in the literature [36], in this case for use in fuel cells.

Sulfonation of both nanofibers and activated carbons was carried out under the same conditions as in the case of HTC to give SCNF, SNor and SElor.

\section{Figure 2 near here}

A summary of the chemical composition and the textural properties of all the catalysts is collected in Table 1 . The values obtained in the analysis of the commercially available catalysts are in agreement with data provided by the supplier and those reported in the literature, as well as the surface area determined by BET, with the only 
exception of SAC-13, whose area is significantly lower than the value $\left(399 \mathrm{~m}^{2} \mathrm{~g}^{-1}\right)$ described for the first time [11]. The BET surface area of SHTC is very low $\left(4 \mathrm{~m}^{2} / \mathrm{g}\right)$, comparable to those reported in the literature both for sulfonated hydrothermal [20] and pyrolyzed carbons at low temperatures [27,37,38], but $\mathrm{CO}_{2}$ adsorption isotherms have shown that this material possesses ultramicropores, with an estimated surface area of $224 \mathrm{~m}^{2} / \mathrm{g}$ [33]. Moreover, these ultramicropores are not permanent, as the accessibility to the acidic sites is controlled by the solvent, as demonstrated by the lack of adsorption of triethylphosphine oxide (TEPO) from hexane and the access to the sites from methanol solutions [33]. This behavior has been explained by the existence of a dense network of hydrogen bonded acid sites, which is broken by solvents with hydrogen bond donor-acceptor character, such as methanol or water. With the two activated carbons, Norit and Elorit, the situation is the opposite, as they show very high surface area and pore volume determined by $\mathrm{N}_{2}$ adsorption, whereas the values are significantly lower when determined by $\mathrm{CO}_{2}$ adsorption, in agreement with a stable structure of supermicropores $(0.7-2 \mathrm{~nm})$ formed by covalent bond. The values of surface area and pore volume after sulfonation are only slightly lower. Both activated carbons show a very low content of sulfur (below $0.2 \%$ ) that was significantly increased upon sulfonation.

\section{Table 1 near here}

Acidity was determined by two methods. The sulfur analysis (Tables 1 and 2) represents the acidity due to sulfonic groups, considering that all the sulfur is present in +6 oxidation state, as determined by XPS [33]. The total acidity of the solids (Table 2) was determined by addition of an excess of $\mathrm{NaOH}$ and potentiometric back titration of the excess of base with potassium hydrogen phthalate. In general, these values are in excellent agreement with the sulfur content determined by chemical analysis in the case of inorganic solids (SAC-13, DI9 and PPS) and the macroreticular A15 polymer. The acidity determined by titration is somehow lower than the sulfur content in the case of D50, probably by some accessibility problems in the inner part of the resin particles due to poor swelling ability in water suspension.

On the other hand, the total acidity of carbons is significantly higher than the sulfur content, between 2.5 and 3.6 times in graphitic carbons (SCNF, SNor and SElor) and almost 10 times in SHTC, because of the presence of other acidic groups, such as 
carboxylic or phenolic ones, produced in the hydrothermal synthesis and during the sulfonation process [33]. A similar oxidation on the graphitic structure of CNT, leading to phenols and carboxylic groups, can be invoked for the non-sulfonic acidity. In view of those results, HTC before sulfonation (acidity $3.42 \mathrm{mmol} / \mathrm{g}$, Table 2) was also considered for catalytic tests, as well as Dowex CCR-2 (CCR) as a model for welldefined carboxylic sites.

\section{Table 2 near here}

The nature of the sulfonic groups in SHTC is uncertain and difficult to analyze. One possibility to determine the acid strength is the adsorption of triethylphosphine oxide (TEPO) from a solution in a non-polar solvent, such as hexane or dichloromethane. It has been described that alkylsulfonic groups give TEPO ${ }^{31} \mathrm{P}$ chemical shift in the range of 71-77 ppm, whereas the value for arylsulfonic groups in Amberlyst 15 is $86 \mathrm{ppm}$ [39]. These values were confirmed in the case of the solids used in this work (Figure $3 \mathrm{~A})$. The range of chemical shifts was from $62.3 \mathrm{ppm}$ for the weakly hydrogen bonding silica gel (the support of sulfonic groups in SAC-13 and PSS) up to $89.5 \mathrm{ppm}$ for the highly acidic SAC-13. D50 and A15 gave the same chemical shift, around 88 ppm, whereas the alkylsulfonic groups in DI9 and PSS led to a signal at 76.4 and $74.6 \mathrm{ppm}$ respectively, in good agreement with the values described in the literature for similar solids. Surprisingly, when TEPO was adsorbed on SHTC from a solution in dichloromethane, the spectrum showed only one intense signal at $58 \mathrm{ppm}$ (Figure 3B), at even lower chemical shift than silica, and the same happens with SElor, with the lowest chemical shift (51.7 ppm). A similar signal is obtained upon adsorption on HTC, and the carboxylic resin CCR leads to one intense signal at $55.3 \mathrm{ppm}$ and one weaker one at $72.1 \mathrm{ppm}$. These results seem to indicate some kind of problem of accessibility for TEPO to reach the acid sites under those conditions. The ultramicroporosity detected for SHTC and HTC [33] is probably due to the formation of a dense network of hydrogen bonds. If the solvent is not able to break the network, the sites are not accessible to interact with TEPO, and the same seems to occur with the flexible polyacrylate chains of CCR. When methanol was used as solvent for TEPO adsorption (Figure 3C), the results were completely different. The solids with carboxylic acid groups and no sulfonic groups, CCR and HTC, show signals at around 64 ppm, in agreement with the chemical shift on a weak acid such as silica. In the case of D50, the signal keeps its chemical shift (88.3 vs 87.8 ppm), although the adsorption in methanol 
produces a narrower signal. Finally, TEPO adsorbed on SHTC produces a signal at 86.2 ppm, in agreement with the existence of arylsulfonic groups, and it also shows a very broad shoulder, that must correspond to TEPO adsorbed on weaker sites, typically carboxylic ones. In fact, this signal significantly increases when the amount of TEPO adsorbed is greater (spectrum not shown). This corroborates the hypothesis that a polar solvent breaks the network of hydrogen bonds, rendering sulfonic surface groups accessible. On the contrary, the adsorption on SElor is not modified by the solvent, indicating in this case the existence of a stable microporosity, as determined by $\mathrm{N}_{2}$ adsorption.

Figure 3 near here

\subsection{Catalytic performance and recovery}

All the solids were tested in the esterification of palmitic acid with methanol as solvent under reflux. As expected, carboxylic CCR does not catalyze the esterification (the results are the same as in a blank reaction), as happens with HTC, which does not contain sulfonic groups but only carboxylic groups. These results rule out the possible role of this kind of weak acid groups as catalysts for esterification. Hence the performance of the different sulfonic solids was quantified as TOF (initial turnover frequency calculated from conversion data at short reaction time, that is the initial linear part of the ester yield vs time curve) with respect to the amount of sulfur (Table 2). The amount of catalyst in each reaction was modified to have similar amounts of active sites.

TOF result obtained with SAC-13 is lower than those reported by Brown and coworkers [5], but of the same order of magnitude, $41.5 \mathrm{vs} 80 \mathrm{~h}^{-1}$. This difference can be ascribed to the different reaction conditions, mainly in the methanol/fatty acid ratio, 10:1 in our case and 44:1 in [5]. On the contrary, the value obtained for A15 perfectly agrees (5.0 vs $4.8 \mathrm{~h}^{-1}$ ) with that reported in [5], in spite of the different reaction conditions. The rest of sulfonic solids, D50, DI9, PSS, shows almost the same TOF values, in the range of 28-30 $\mathrm{h}^{-1}$, with no significant effect of the type of support and sulfonic nature (aromatic or aliphatic). SCNF also leads to a TOF value in the same range. This seems to indicate that significant improvements in the catalytic performance of sulfonic solids for this kind of reaction are produced only in the case of differences in acidity of several units of $\mathrm{H}_{0}$, such as in the perfluorinated SAC-13. On the contrary, the TOF values obtained 
with SElor $\left(14.2 \mathrm{~h}^{-1}\right)$, SNor and A15 $\left(5 \mathrm{~h}^{-1}\right)$ are lower than expected. These exceptions may be related to their rigid structure, microporous in the case of sulfonated activated carbons, and possible limitations in the accessibility to a big part of the catalytic sites.

Surprisingly the sulfonic sites in SHTC are significantly more active than the others, leading to a TOF value $\left(127.2 \mathrm{~h}^{-1}\right)$ much higher than that obtained for SAC-13. This result was fully reproducible $\left( \pm 10 \mathrm{~h}^{-1}\right)$ with the same and 10 different batches of SHTC having values of sulfur analysis of $0.52 \pm 0.08 \mathrm{mmol} / \mathrm{g}$. This TOF value $\left(127.2 \mathrm{~h}^{-1}=\right.$ $3.5 \times 10^{-2} \mathrm{~s}^{-1}$ ) is only slightly lower than those recently described for homogeneous arylsulfonic catalyst [40]. Under the high dilution conditions required for homogeneous catalysis (due to solubility problems), the TOF obtained with SHTC is significantly lower $\left(0.5 \times 10^{-2} \mathrm{~s}^{-1}\right.$ vs $8.8 \times 10^{-2} \mathrm{~s}^{-1}$ with $p$-toluensulfonic acid in our own experiment under the conditions of ref. 38), but on the contrary, the high concentrated conditions used for SHTC are not suitable for arylsulfonic acids due to their low solubility.

The catalysts were recovered and reused under the same conditions, and they showed completely different behaviors (TOF calculated with respect to sulfur analysis of the fresh catalyst, Table 2). On the one hand, in some of the solids the sulfonic groups show nearly the same performance as in the fresh catalysts, namely SAC-13, DI9, PSS and A15, with slight decreases in rate attributable to weight loss of catalyst in the filtration process. On the contrary, the rest of the solids, showed a significant decrease in performance upon recovery, with only $30-45 \%$ of the initial TOF. As described in a previous work [22], the drastic decrease in efficiency of SHTC is not due to leaching of active species, demonstrated by the lack of deactivation after Soxhlet treatment with different solvents and the lack of catalytic activity of the leachates. Thus, to shed further light into the deactivation process, first the reaction with methanol of the different solids was explored.

\subsection{Deactivation with methanol}

In a previous work, the deactivation of SHTC was mainly attributed to the formation of methyl sulfonate groups on the surface [22], with the consequent decrease in acidity. Following this idea, the catalysts were treated with methanol under reflux for $72 \mathrm{~h}$ and then characterized to compare their acidic properties and catalytic performance with the fresh solids (Table 3). 
Sulfur analyses were very similar to the untreated catalysts, with more than $85 \%$ of the starting value and the highest discrepancies in the solids (SAC-13, SCNF) with lower content, more prone to error in determination. With regard to catalytic performance per sulfonic site (Table 3), deactivation was very significant in some of the catalysts that showed deactivation under reaction conditions, D50, SHTC and SCNF, whereas the rate per sulfonic site remained constant with the rest of the solids and only slightly reduced in the case of SAC-13. This result indicates that methanol is the main factor responsible for deactivation under reaction conditions in the case of D50, SHTC and SCNF, and rules out the role of fatty acid derivatives adsorption $[18,28]$ or leaching of active species $[27,41]$ proposed in other cases. Sulfonated activated carbons, SNor and SElor, show no deactivation by treatment with methanol whereas they are significantly deactivated under reaction conditions. This indicates the different nature of the deactivation, which can be ascribed to the pore blocking $[18,28]$ due to the high micropore volume of the solids. This hypothesis is in good agreement with the loss in surface area (from 925 to $660 \mathrm{~m}^{2} \mathrm{~g}^{-1}$ for SNor; from 637 to $364 \mathrm{~m}^{2} \mathrm{~g}^{-1}$ for SElor) and pore volume (from 0.747 to $0.619 \mathrm{~cm}^{3} \mathrm{~g}^{-1}$ for SNor; from 0.538 to $0.381 \mathrm{~cm}^{3} \mathrm{~g}^{-1}$ for SElor) when recovered after two reactions.

${ }^{13} \mathrm{C}$ CP-MAS-NMR was used to check the presence of methyl groups in the treated solids. In the case of solids that are not deactivated in methanol, either they do not show any additional signal (A15, Figure S1, supplementary material) or a new signal is observed at 49-51 ppm (Figures 4 and S2), compatible with a MeO-group, either as adsorbed methanol or as methyl ester. When the samples were thoroughly treated under vacuum (for different times, depending on the sample), the new signal disappeared, indicating that methanol remains adsorbed on sulfonic solids, probably linked to the sulfonic acid groups by hydrogen bonds, but this adsorption is reversible and not responsible for any deactivation of the catalyst.

\section{Figure 4 near here}

In the spectrum of D50 treated with methanol (Figure 5A) a signal at $58 \mathrm{ppm}$ is observed, that fits well with the chemical shift of a $\mathrm{SO}_{3} \mathrm{Me}$ group (56.2 ppm in methyl $p$-toluenesulfonate). The assignation of the new signal in SHTC (Figure 5B) is less clear, as it appears at $52.5 \mathrm{ppm}$. When these samples were thoroughly treated under 
vacuum, the intensity of the new signal was not reduced, showing that the methyl group is more tightly bound to the surface, probably through a covalent bond. Interestingly, a similar result is obtained with the highly flexible CCR solid (Figure S3), in agreement with the same behavior of this solid with respect to the accessibility of TEPO. These results reinforce the hypothesis of a strong network of hydrogen bonds between the acid sites in SHTC and CCR, that must be broken to allow the access of TEPO, and the proximity of the acid sites allows the esterification of the sites of the solid, either sulfonic or carboxylic.

Figure 5 near here

A low-intensity spectrum could be recorded for SElor and SNor after reaction, and no methyl band was observed (Figure S4), confirming again the existence of a second deactivation mechanism for those solids.

\subsection{Mechanism of surface esterification}

Considering the formation or not of surface methyl esters, a question arises: which is the mechanism for this reaction? The initial protonation of the alcohol was discarded by using an alcohol able to form a much more stable carbocation, such as benzyl alcohol. It reacts on DI9 to give a polymer, with a typical signal for $\mathrm{Ar}-\mathrm{CH}_{2}-\mathrm{Ar}$ group at around 40 ppm (Figure 6), by the usual Friedel-Crafts alkylation mechanism through the benzylic carbocation. The lack of ester on DI9 demonstrates that the esterification of the surface acidic groups does not take place through protonation of the alcohol. On SHTC, with sulfonic sites able to protonate the neighboring acids, the reaction produces a signal at 67 ppm, which fits well with the expected chemical shift of a surface benzyl ester. Moreover, the signal is not reduced after thorough washing with toluene and treatment under vacuum, showing that this species is probably bound by covalent bond to the surface and confirming again the special nature of the surface sites on SHTC. Unexpectedly, treatment of D50 with benzyl alcohol does not give rise to the ester signal, but to a modification of the resin (Figure S5), probably due to Friedel-Crafts alkylation of the aromatic groups of the polystyrene backbone. The treatment of SElor did not produce any remarkable change in the spectrum of the solid catalyst (not shown). 
The classical acid catalyzed esterification mechanism (Scheme 1, eq. 1) consists of a protonation of the carboxylic acid with the catalyst, the attack of the alcohol on the carbocation, leading to a tetrahedral intermediate, and a final elimination of water with regeneration of the acid catalyst. This mechanism is also generally accepted for heterogeneous acid catalysts, although some controversy exists about the need for adsorption of the alcohol (Langmuir-Hinshelwood mechanism) [42] or not (Eley-Rideal mechanism) [43].

The only way to esterify the acidic groups (both carboxylic and sulfonic ones) on a solid is in the case that at least two groups are close enough to transfer a proton (Scheme 1, eq. 2 and 3). Treatment of sulfonic solids with low surface density of sulfonic sites (see Table 1), such as DI9 (490 m²/g, 1.0 sites $\left./ \mathrm{nm}^{2}\right)$, PSS (307 m²/g, $\left.1.5 \mathrm{sites} / \mathrm{nm}^{2}\right)$ or SAC$13\left(99 \mathrm{~m}^{2} / \mathrm{g}, 1.0\right.$ sites $\left./ \mathrm{nm}^{2}\right)$, should not produce any surface ester formation. On the contrary, solids with high surface density of sulfonic/carboxylic sites should be very prone to the formation of surface sulfonic esters.

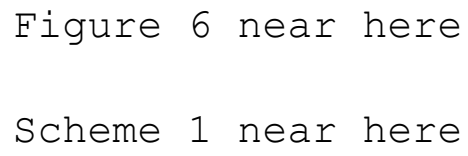

The different behavior of D50 and A15, sulfonated polystyrene in both cases, should rely on the mobility of the polystyrene chains. In the case of the low cross-linked D50, the gel nature of the resin, with a significant conformational freedom of the sulfonated polystyrene chains, allows their approach and the interaction between the sulfonic groups, whereas the more rigid structure of the high cross-linked A15 hampers this approach. In fact, other authors had described different deactivation rates in the ethanol dehydration reaction catalyzed by sulfonated polystyrene resins depending on the surface density of sulfonic sites, with slower deactivation in the case of solids with low density of sites [44]. In that case, other deactivation mechanisms had been proposed, such as inhibition by water formation, although the formation of ethyl sulfonic esters on the surface might be also a mechanism participating in the deactivation. In the case of SCNF, the measured surface area $\left(150 \mathrm{~m}^{2} / \mathrm{g}\right)$ gives an average sulfonic site distribution of only 0.3 sites $/ \mathrm{nm}^{2}$. However, given the nature and morphology of the nanofibers, it is highly probable that the sites are concentrated in the edges of graphitic planes, as well as in the defects of graphene planes, leading to high local surface concentration of sites. 
In the case of SHTC, the existence of the hypothetical dense network of hydrogen bonded acid sites, would be in agreement with the close proximity of the acid sites, responsible for the deactivation by methyl ester formation on the surface.

In principle, both carboxylic and sulfonic esters could be formed. SHTC deactivated by treatment with methanol was studied by XPS (Figures S6-S8). The C1s and S2p peaks did not show any significant difference with respect to the freshly prepared catalyst. The $\mathrm{O} 1 \mathrm{~s}$ peak showed an increase in the $\mathrm{C}-\mathrm{O} / \mathrm{C}=\mathrm{O}$ ratio, in agreement with the formation of new $\mathrm{O}-\mathrm{CH}_{3}$ bonds, although by this technique it is impossible to know if they are sulfonic or carboxylic esters. As sulfonic groups are the stronger ones, and hence responsible for the catalytic activity, their elimination by esterification should have the largest impact on the performance. This was confirmed by TEPO adsorption from methanol solution (Figure 7). As can be seen, when 0.8 equivalents (with respect to sulfur content) of TEPO are adsorbed on SHTC from methanol solution, most of them are protonated by the accessible sulfonic groups leading to a signal at around $87 \mathrm{ppm}$. The rest interacts with carboxylic groups leading to a weak signal at around $65 \mathrm{ppm}$. After treatment with methanol under reflux, the situation is reversed, with most of TEPO protonated by the weak carboxylic groups and only a minor fraction is able to interact with the sulfonic groups, in agreement with their deactivation by methyl ester formation. However, the decrease in total acidity from 5.43 (Table 1) to $4.14 \mathrm{mmol} / \mathrm{g}$ (Table 3), indicates that at least one part of the esters are formed in the carboxylic acid groups.

$$
\text { Figure } 7 \text { near here }
$$

\subsection{Kinetic studies}

The experiments described above explain the reason for the deactivation of solids having high surface density of sulfonic sites in alcoholic media, but they do not give a clue about the higher initial rate per sulfonic site obtained with SHTC in comparison with the rest of the sulfonic solids. In view of that, the kinetics using SHTC and DI9 were compared. The volume of the reaction mixture was adjusted with dioxane and the reaction order for each reactant was determined from the initial reaction rate (in $\mathrm{mol} \mathrm{L}^{-1}$ $\mathrm{s}^{-1}$ ) by varying the concentration of one of them while keeping constant that of the other one (Table 4). With those data, the apparent reaction orders in the case of DI9 are 0.91 for methanol and 1.56 for palmitic acid, whereas for SHTC are 1.27 for methanol and 
1.81 for palmitic acid. These results are in contrast with those reported for the esterification of acetic acid with methanol: in the case of sulfonated SBA-15, reaction orders of 0.72 and 0.87 , for methanol and acetic acid respectively [42], and values even lower ( 0.59 and 0.74 respectively) in the case of SAC-13 [43]. The origin for these high apparent reaction orders, even higher than 1, is currently under investigation. In view of that, the reaction order with respect to catalyst amount was also determined by changing the amount of catalyst used (Table 4 ). The obtained value, $1 \pm 0.1$, was expected for this type of reaction. A further demonstration of the higher intrinsic catalytic activity of sulfonic groups in SHTC is the higher initial reaction rate than in the case of DI9 $\left(1.22 \times 10^{-5}\right.$ vs $0.67 \times 10^{-5} \mathrm{M} \mathrm{s}^{-1}$ respectively) with the same amount of sulfonic sites and at $1 \mathrm{M}$ concentration of both reagents, to eliminate any effect of the apparent reaction order. Of course the difference increases at higher concentrations of reagents as a result of the higher apparent reaction order in SHTC.

\section{Table 4 near here}

It is difficult to propose a reason for this higher efficiency, but it might be related to the high surface concentration of sulfonic and other weaker acidic sites. Brown and coworkers have determined the acidity and catalytic activity of different types of solids (polystyrene resins, functionalized inorganic materials) with variable sulfonation levels $[16,24,45]$. In general, they have observed an increase in both acid strength and catalytic activity at higher content of sulfonic groups, and they have explained these effects by the existence of networks of interacting sulfonic groups, as seems to happen in the case SHTC. Over-sulfonation of polystyrene resins (more than one sulfonic group per aromatic ring in average) has the same effect, although in that case the intrinsic higher acidity of the sulfonic groups due to the presence of the second electron-withdrawing (sulfonic) group in the aromatic ring was invoked [46]. Carboxylic acids in close proximity to sulfonic groups could have this same effect. The proximity effect has been also demonstrated on a mesoporous silica by synthesis from a disulfide precursor [17].

Carbons prepared by incomplete pyrolysis of glucose and subsequent sulfonation also show both kinds of acidity, sulfonic and carboxylic, and they have been described as catalysts in the esterification of oleic acid with ethanol [19]. Thus, SHTC was tested in the esterification of palmitic acid with ethanol with a double objective, to broad the scope of the catalyst and to compare its performance with that of the carbons with a 
different content of carboxylic sites. The TOF obtained with SHTC, $38.2 \mathrm{~h}^{-1}$, was significantly lower than in the case of methanol, in agreement with the lower reactivity of this alcohol, but in any case it was higher than the values reported in the literature (18.9 and $21.5 \mathrm{~h}^{-1}$ ) for carbons with different composition [19]. The plot of TOF vs. acidity did not show any correlation, except in the case of using the content of carboxylic sites (Figure 8). The perfect correlation obtained prompted us to test also a solid without carboxylic sites, such as D50, whose activity fit very well with the expected value (Figure 8). This result supports the hypothesis of a cooperative role of carboxylic sites with sulfonic ones. Moreover, the formation of surface methyl esters in the deactivation process would not only eliminate active sulfonic sites by forming sulfonate groups, but it would also eliminate the cooperative effect through the formation of carboxylate groups, acting the remaining sulfonic sites as isolated groups.

\section{Figure 8 near here}

\subsection{Stability against water and improved recoverability}

Water is the concomitant product of the esterification reaction, and it is well-known the detrimental effect of the presence of water in the reaction medium [43]. The peculiar properties of SHTC prompted us to study the effect of water in the reaction medium in comparison with a typical sulfonic solid, such as DI9. Reactions were carried out under the optimal conditions (methanol/palmitic acid molar ratio $=10: 1$, without solvent) with increasing amounts of water up to water/palmitic acid molar ratio $=1: 1$. The results are represented in Figure 9. The initial reaction rate with SHTC decreases up to 50\% with 1 equivalent of water, whereas the initial rate with DI9 is only $33 \%$ of the rate in the absence of water. It can be seen that even in the presence of one equivalent of water, SHTC performs better than DI9 in anhydrous medium. The enhancement in the stability against water has been also recently described in homogeneous phase with $p$-sulfonic acid calix $[n]$ calixarenes in comparison with the analogous monomeric $p$ hydroxybenzene sulfonic acid [40]. In such case, the presence of undissociated hydroxyls able to trap the water by hydrogen bonding has been proposed as the origin of the enhanced stability. In SHTC the presence of carboxylic acids may play a similar role.

$$
\text { Figure } 9 \text { near here }
$$


Regarding recoverability, the improvement of this aspect of the SHTC catalyst is a question of competitive kinetics between the esterification of palmitic acid and the esterification of the surface acid sites. Unfortunately, it is not possible to determine the kinetic parameters of the latter, but it can be speculated that the kinetic parameters probably will be different from those of the esterification of the soluble acid. Thus, some conditions, such as the methanol and palmitic acid concentrations and the reaction time may affect the two reactions in different way. In fact, the recovery of SHTC after a reaction under concentrated conditions (10:1 methanol/palmitic ratio, without diluting solvent, 24 h) shows only a $45 \%$ of the original initial rate. Dilution with dioxane $\left(\mathrm{V}_{\text {dioxane }}=\mathrm{V}_{\mathrm{MeOH}}\right)$ and reduction of reaction time to $8 \mathrm{~h}$ ( $88 \%$ yield $)$ improves recoverability to $79 \%$ of the initial rate ( $83 \%$ of the final yield), due to the reduced exposure of the catalyst to methanol, although the third reaction proceeds with only $25 \%$ of the original initial rate. Given the results in the presence of water, it can be speculated that a small amount of water may help to enhance the stability of the solid to recovery by partial inhibition of the esterification of surface groups, whereas keeping a high performance. In Figure 10 the recovery in the presence (water/palmitic acid molar ratio $=0.6)$ and in the absence of water are compared. It can be seen that in the first reaction the presence of water has a slight detrimental effect described above, but in the second run both reactions, with and without water, show the same performance, representing $70 \%$ of the initial rate for the catalyst used in the presence of water. More interestingly, the drop in performance in the third run is quite low, showing the $60 \%$ of the initial rate, even after $48 \mathrm{~h}$ ( $24 \mathrm{~h}$ each run) in contact with methanol.

$$
\text { Figure } 10 \text { near here }
$$

\section{Conclusions}

Sulfonated hydrothermal carbon (SHTC) is a highly promising acidic solid for esterification of fatty acids. Its sulfonic sites lead to a much higher TOF than those of related solids, such as sulfonic resins, and even stronger acids as SAC-13 bearing perfluorinated alkylsulfonic groups. Although the reasons for this behavior are not clear enough, the high surface density of sulfonic sites, probably in cooperation with weak acid sites (carboxylic and/or phenolic groups), seems to be the main factor. This proximity is demonstrated by the need of using a highly polar (or even polar protic) solvent to get access to the acidic site, as demonstrated by the experiments of TEPO 
adsorption, and responsible the non-permanent ultramicroporosity determined by $\mathrm{CO}_{2}$ adsorption. At the same time the catalyst keeps a high efficiency even in the presence of significant amounts of water, whereas a typical sulfonic solid suffers a deep inhibition under the same conditions. Unfortunately, the proximity of sites, consequence of the high surface density, produces the esterification on the surface acid groups as side reaction, leading to an irreversible deactivation of the catalyst. A decrease in the initial methanol concentration and reaction time or the presence of small amounts of water inhibit more efficiently the esterification of the surface sites than the fatty acid esterification, allowing a better recoverability while keeping a high catalytic performance. Further research is currently in progress in our laboratories to better understand the origin of the enhanced efficiency of the sulfonic sites in SHTC and to design an optimized catalyst with similar performance and improved recoverability, as well as the application of SHTC to other reactions that do not involve the use of alcohols.

\section{Acknowledgement}

This work was made possible by the financial support of the Spanish Ministerio de Economía y Competitividad (project CTQ2011-28124), the European Commission (FREECATS project, grant agreement No. 280658) and the Gobierno de Aragón (Group E11).

\section{References}

[1] A. Corma, Chem. Rev. 95 (1995) 559-614.

[2] G. Busca, Chem. Rev. 107 (2007) 5366-5410.

[3] Fine Chemicals through Heterogeneous Catalysis; R. A. Sheldon, H. van Bekkum (Eds.); Wiley-VCH; Weinheim, 2001.

[4] G. Gelbard, Ind. Eng. Chem. Res. 44 (2005) 8468-8498.

[5] E. Andrijanto, E. A. Dawson, D. R. Brown, Appl. Catal. B 114-116 (2012) 261-268.

[6] P. F. Siril, H. E. Cross, D. R. Brown, J. Mol. Catal. A 279 (2008) 63-68.

[7] M. A. Harmer, Q. Sun, Appl. Catal. A 221 (2001) 45-62.

[8] R. D. Badley, W. T. Ford, J. Org. Chem. 54 (1989) 5437-5443.

[9] M. H. Lim, C. F. Blanford, A. Stein, Chem. Mater. 10 (1998) 467-470. 
[10] For a review see: J. A. Melero, R. van Grieken, G. Morales, Chem. Rev. 106 (2006) 3790-3812.

[11] M.A. Harmer, Q. Sun, W.E. Farneth, J. Am. Chem. Soc. 118 (1996) 7708-7715.

[12] M. Hara, T. Yoshida, A. Takagaki, T. Takata, J. N. Kondo, S. Hayashi, K. Domen, Angew. Chem. Int. Ed. 43 (2004) 2955-2958.

[13] K. Tanabe, W. F. Hölderich, Appl. Catal. A 181 (1999) 399-434.

[14] K. Suwannakarn, E. Lotero, K. Ngaosuwan, J. G. Goodwin Jr., Ind. Eng. Chem. Res. 48 (2009) 2810-2818.

[15] C. V. Grossi, E. O. Jardim, M. H. de Araújo, R. M. Lago, M. J. da Silva, Fuel 89 (2010) 257-259.

[16] P. F. Siril, N. R. Shiju, D. R. Brown, K. Wilson, Appl. Catal. A 364 (2009) 95-100.

[17] I. K. Mbaraka, B. H. Shanks, J. Catal. 244 (2006) 78-85.

[18] Y. Liu, E. Lotero, J. G. Goodwin Jr., J. Catal. 243 (2006) 221-228.

[19] A. Takagaki, M. Toda, M. Okamura, J. N. Kondo, S. Hayashi, K. Domen, M. Hara, Catal. Today 116 (2006) 157-161.

[20] J. A. Maciá-Agulló, M. Sevilla, M. A. Diez, A. B. Fuertes, ChemSusChem 3 (2010) 1352-1354.

[21] L. Peng, A. Philippaerts, X. Ke, J. Van Noyen, F. De Clippel, G. Van Tendeloo, P. A. Jacobs, B. F. Sels, Catal. Today 150 (2010) 140-146.

[22] J. M. Fraile, E. García-Bordejé, L. Roldán, J. Catal. 289 (2012) 73-79.

[23] L. Roldán, I. Santos, S. Armenise, J. M. Fraile, E. García-Bordejé, Carbon 50 (2012) 1363-1372.

[24] S. Koujout, D. R. Brown, Catal. Lett. 98 (2004) 195-202.

[25] P. F. Siril, A. D. Davison, J. K. Randhawa, D. R. Brown, J. Mol. Catal. A 267 (2007) 72-78.

[26] M.-H. Zong, Z.-Q. Duan, W.-Y. Lou, T. J. Smith, H. Wu, Green Chem. 9 (2007) 434-437.

[27] X. Mo, D. E. López, K. Suwannakarn, Y. Liu, E. Lotero, J. G. Goodwin Jr., C. Lu, J. Catal. 254 (2008) 332-338.

[28] A. C. Alba-Rubio, F. Vila, D. Martín Alonso, M. Ojeda, R. Mariscal, M. López Granados, Appl. Catal. B 95 (2010) 279-287.

[29] A. Chakrabarti, M. M. Sharma, React. Polym. 20 (1993) 1-45.

[30] S. Wieland, P. Panster, Stud. Surf. Sci. Catal. 108 (1997) 67-74. 
[31] K. Wilson, A. F. Lee, D. J. Macquarrie, J. H. Clark, Appl. Catal. A 228 (2002) 127-133.

[32] N. Baccile, G. Laurent, F. Babonneau, F. Fayon, M.-M. Titirici, M. Antonietti, J. Phys. Chem. C 113 (2009) 9644-9654.

[33] J. M. Fraile, E. García-Bordejé, E. Pires, L. Roldán, Carbon 77 (2014) 1157-1167.

[34] R. L. Johnson, J. M. Anderson, B. H. Shanks, X. Fang, M. Hong, K. Schmidt-Rohr, J. Magn. Reson. 234 (2013) 112-124.

[35] N. M. Rodriguez, J. Mater. Res. 8 (1993) 3233-3250.

[36] T. F. Hung, S. H. Liao, C. Y. Li, Y. W. Chen-Yang, J. Power Sources 196 (2011) $126-132$.

[37] S. Suganuma, K. Nakajima, M. Kitano, D. Yamaguchi, H. Kato, S. Hayashi, M. Hara, J. Am. Chem. Soc. 130 (2008) 12787-12793.

[38] M. Kitano, D. Yamaguchi, S. Suganuma, K. Nakajima, H. Kato, S. Hayashi, M. Hara, Langmuir 25 (2009) 5068-5075.

[39] D. Margolese, J. A. Melero, S. C. Christiansen, B. F. Chmelka, G. D. Stucky, Chem. Mater. 12 (2000) 2448-59.

[40] R. Natalino, E. V. V. Varejão, M. J. da Silva, A. L. Cardoso, S. A. Fernandes, Catal. Sci. Technol. 4 (2014) 1369-1375.

[41] W. Zhang, H. Tao, B. Zhang, J. Ren, G. Lu, Y. Wang, Carbon 49 (2011) 18111820 .

[42] S. Miao, B. H. Shanks, J. Catal. 279 (2011) 136-143.

[43] Y. Liu, E. Lotero, J. G. Goodwin Jr., J. Catal. 242 (2006) 278-286.

[44] Y. C. Chee, S. K. Ihm, J. Catal. 102 (1986) 180-189.

[45] S. Koujout, B. M. Kiernan, D. R. Brown, H. G. M. Edwards, J. A. Dale, S. Plant, Catal. Lett. 85 (2003) 33-40.

[46] M. Hart, G. Fuller, D. R. Brown, J. A. Dale, S. Plant, J. Mol. Catal. A 182-183 (2002) 439-445. 
Table 1. Elemental analysis and textural properties of the solids. ${ }^{a}$

\begin{tabular}{lccccccc}
\hline Solid & $\% \mathrm{C}$ & $\% \mathrm{H}$ & $\% \mathrm{~S}$ & \multicolumn{2}{c}{$\mathrm{BET}\left(\mathrm{N}_{2}\right)$} & \multicolumn{2}{c}{$\mathrm{CO}_{2}$ ads. } \\
\cline { 5 - 8 } & & & & $\mathrm{S}_{\mathrm{A}}$ & $\mathrm{V} \mathrm{p}$ & $\mathrm{S}_{\mathrm{A}}$ & $\mathrm{V}_{\mathrm{p}}$ \\
\hline SAC-13 & 3.60 & 0.68 & 0.52 & 99 & 0.407 & - & - \\
D50 & 51.75 & 4.81 & 16.95 & - & - & - & - \\
A15 & 50.68 & 5.52 & 15.23 & 42 & 0.355 & - & - \\
DI9 & 4.17 & 1.59 & 2.57 & 490 & 0.587 & - & - \\
PSS & 3.14 & 1.22 & 2.16 & 307 & 0.594 & - & - \\
SCNF & 94.34 & 0.27 & 0.27 & 150 & 0.397 & - & - \\
SHTC & 58.91 & 2.10 & 1.90 & 4 & 0.009 & 224 & 0.090 \\
SNor & 84.63 & 0.40 & 0.64 & 925 & 0.747 & 585 & 0.235 \\
SElor & 80.85 & 0.85 & 1.21 & 637 & 0.538 & - & - \\
HTC & 66.34 & 4.40 & 0.00 & 7 & 0.014 & 142 & 0.060 \\
Norit & 83.70 & 1.10 & 0.08 & 948 & 0.767 & 581 & 0.234 \\
Elorit & 86.48 & 0.81 & 0.19 & 727 & 0.579 & - & -
\end{tabular}

${ }^{\text {a }}$ Textural properties determined by $\mathrm{N}_{2}$ adsorption at $77 \mathrm{~K}(\mathrm{BET})$ or $\mathrm{CO}_{2}$ adsorption at room temperature. $\mathrm{S}_{\mathrm{A}}=$ surface area $\left(\mathrm{m}^{2} \mathrm{~g}^{-1}\right) . \mathrm{V}_{\mathrm{p}}=$ pore volume $\left(\mathrm{cm}^{3} \mathrm{~g}^{-1}\right)$. 
Table 2. Acidity of sulfonic solids and rate per sulfonic site in the esterification of palmitic acid with methanol.

\begin{tabular}{lllll}
\hline Catalyst & $\begin{array}{l}\text { Sulfur content } \\
(\mathrm{mmol} / \mathrm{g})^{\mathrm{a}}\end{array}$ & $\begin{array}{l}\text { Total acidity } \\
(\mathrm{mmol} / \mathrm{g})^{\mathrm{b}}\end{array}$ & \multicolumn{2}{l}{$\mathrm{TOF}\left(\mathrm{h}^{-1}\right)^{\mathrm{c}}$} \\
\cline { 4 - 5 } & 0.17 & 0.18 & 41.5 & 34.3 \\
\hline SAC-13 & 5.30 & 4.46 & 28.3 & 11.3 \\
D50 & 4.76 & 4.40 & 5.0 & 4.8 \\
A15 & 0.80 & 0.78 & 28.1 & 27.5 \\
DI9 & 0.74 & 0.75 & 30.0 & 30.0 \\
PSS & 0.08 & 0.29 & 29.6 & 8.9 \\
SCNF & 0.59 & 5.43 & 127.2 & 48.3 \\
SHTC & 0.20 & 0.65 & 5.1 & 1.2 \\
SNor & 0.38 & 0.97 & 14.2 & 0.7 \\
SElor & 0 & 3.42 & $0.08^{\mathrm{d}}$ & n.d. \\
HTC & 0 & 4.08 & $0.05^{\mathrm{d}}$ & n.d. \\
CCR & 0 & & & \\
\hline
\end{tabular}

${ }^{a}$ Determined by elemental analysis.

${ }^{\mathrm{b}}$ Determined by back titration.

${ }^{\mathrm{c}}$ Mol of palmitic acid converted per mol of sulfur per hour.

${ }^{\mathrm{d}}$ Calculated with respect to the total acidity. 
Table 3. Acidity of the sulfonic solids treated with methanol under reflux (72 h) and rate per sulfonic site in the esterification of palmitic acid with methanol.

\begin{tabular}{llll}
\hline Catalyst & $\begin{array}{l}\text { Sulfur content } \\
(\mathrm{mmol} / \mathrm{g})^{\mathrm{a}}\end{array}$ & $\begin{array}{l}\text { Total acidity } \\
(\mathrm{mmol} / \mathrm{g})^{\mathrm{b}}\end{array}$ & TOF $\left(\mathrm{h}^{-1}\right)^{\mathrm{c}}$ \\
\hline SAC-13 & 0.13 & 0.14 & 31.4 \\
D50 & 5.27 & 4.41 & 11.4 \\
A15 & 5.22 & 4.36 & 4.0 \\
DI9 & 0.72 & 0.73 & 29.2 \\
PSS & 0.65 & 0.68 & 28.9 \\
SCNF & 0.06 & 0.22 & 13.3 \\
SNor & 0.18 & 0.56 & 5.1 \\
SElor & 0.33 & 0.82 & 12.2 \\
SHTC & 0.46 & 4.14 & 9.8 \\
\hline
\end{tabular}

${ }^{a}$ Determined by elemental analysis.

${ }^{\mathrm{b}}$ Determined by back titration.

${ }^{\mathrm{c}}$ Mol of palmitic acid converted per mol of sulfur per hour.

Table 4. Initial reaction rates for the determination of the apparent reaction orders in the esterification of palmitic acid with methanol.

\begin{tabular}{llllll}
\hline & & \multicolumn{2}{c}{ DI9 } & \multicolumn{2}{c}{ SHTC } \\
{$[\mathrm{Palm}]_{0}(\mathrm{M})$} & {$[\mathrm{MeOH}]_{0}(\mathrm{M})$} & $\mathrm{m}_{\text {cat }}(\mathrm{mg})$ & $\mathrm{r}_{0}(\mathrm{M} / \mathrm{s})$ & $\mathrm{m}_{\text {cat }}(\mathrm{mg})$ & $\mathrm{r}_{0}(\mathrm{M} / \mathrm{s})$ \\
\hline 1 & 1 & 47 & $0.67 \times 10^{-5}$ & 83 & $1.22 \times 10^{-5}$ \\
1 & 2 & 47 & $1.25 \times 10^{-5}$ & 83 & $3.37 \times 10^{-5}$ \\
1 & 3 & 47 & $1.89 \times 10^{-5}$ & 83 & $5.31 \times 10^{-5}$ \\
1 & 4 & 47 & $2.27 \times 10^{-5}$ & 83 & $6.91 \times 10^{-5}$ \\
0.75 & 1 & 47 & $0.42 \times 10^{-5}$ & 83 & $0.68 \times 10^{-5}$ \\
1.25 & 1 & 47 & $0.88 \times 10^{-5}$ & 83 & $1.55 \times 10^{-5}$ \\
1.5 & 1 & 47 & $1.27 \times 10^{-5}$ & 83 & $2.54 \times 10^{-5}$ \\
1 & 1 & 23 & $0.29 \times 10^{-5}$ & 55 & $0.91 \times 10^{-5}$ \\
1 & 1 & 70 & $1.09 \times 10^{-5}$ & 28 & $0.44 \times 10^{-5}$ \\
\hline
\end{tabular}




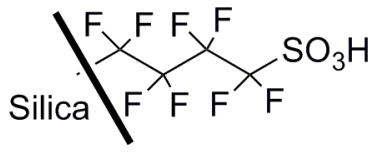

SAC-13<smiles>O=S(=O)(O)CCC[Si](O[Si])(O[Si])O[Si]</smiles>

Deloxan ASP I/9 (DI9)<smiles>CCCC(CC)c1ccc(C(CCC)C(C)(C)C(C)CC(C)C(C)C)cc1</smiles>

(D50): $x=0.02$

Amberlyst 15 (A15): $x=0.20$

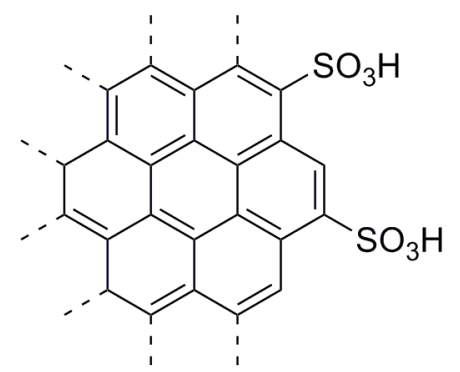

Sulfonated carbon nanofibers (SCNF) Sulfonated activated carbons (SNor, SElor)

Figure 1. Sulfonic solids used in this work.

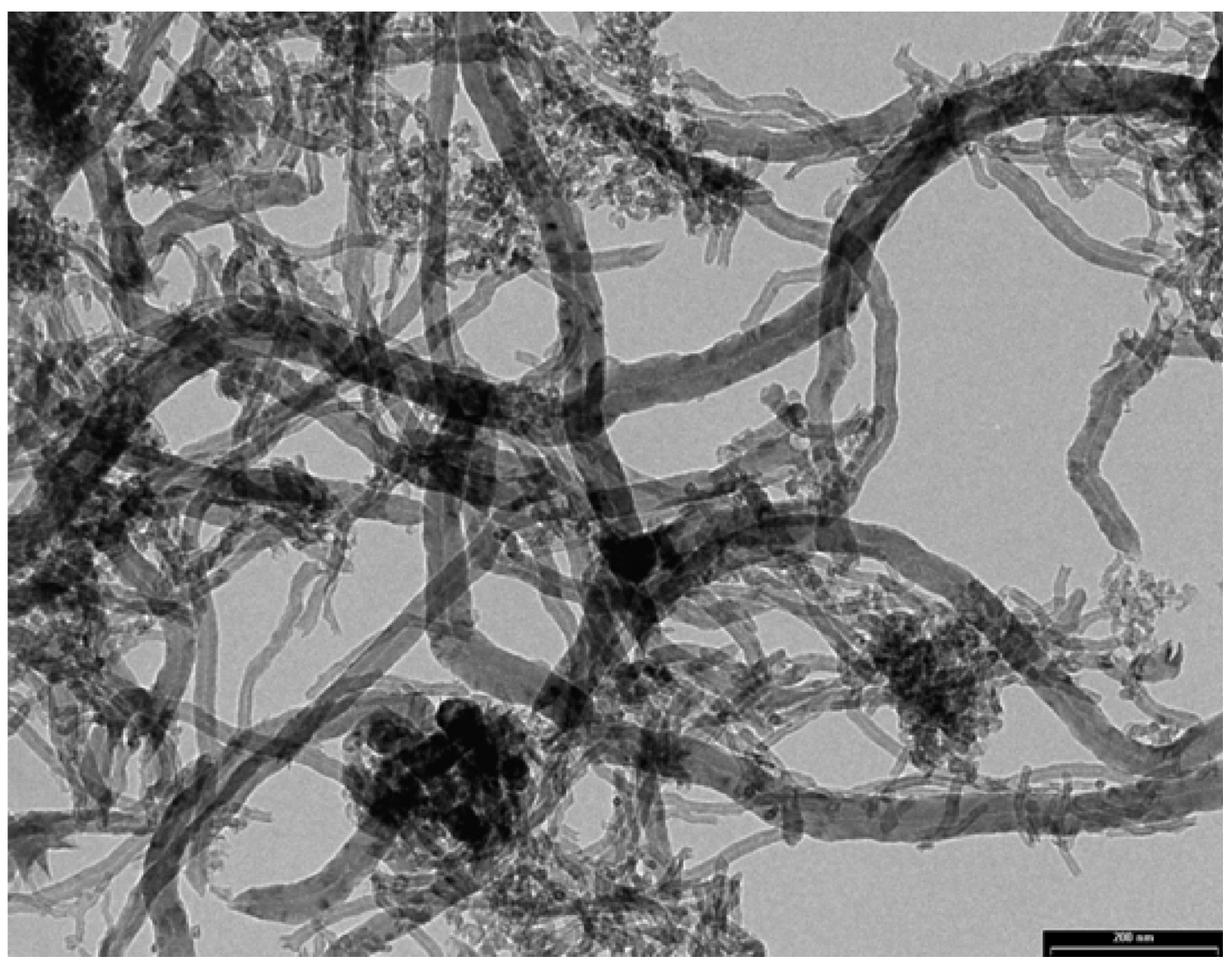

Figure 2. TEM image of purified CNF. 

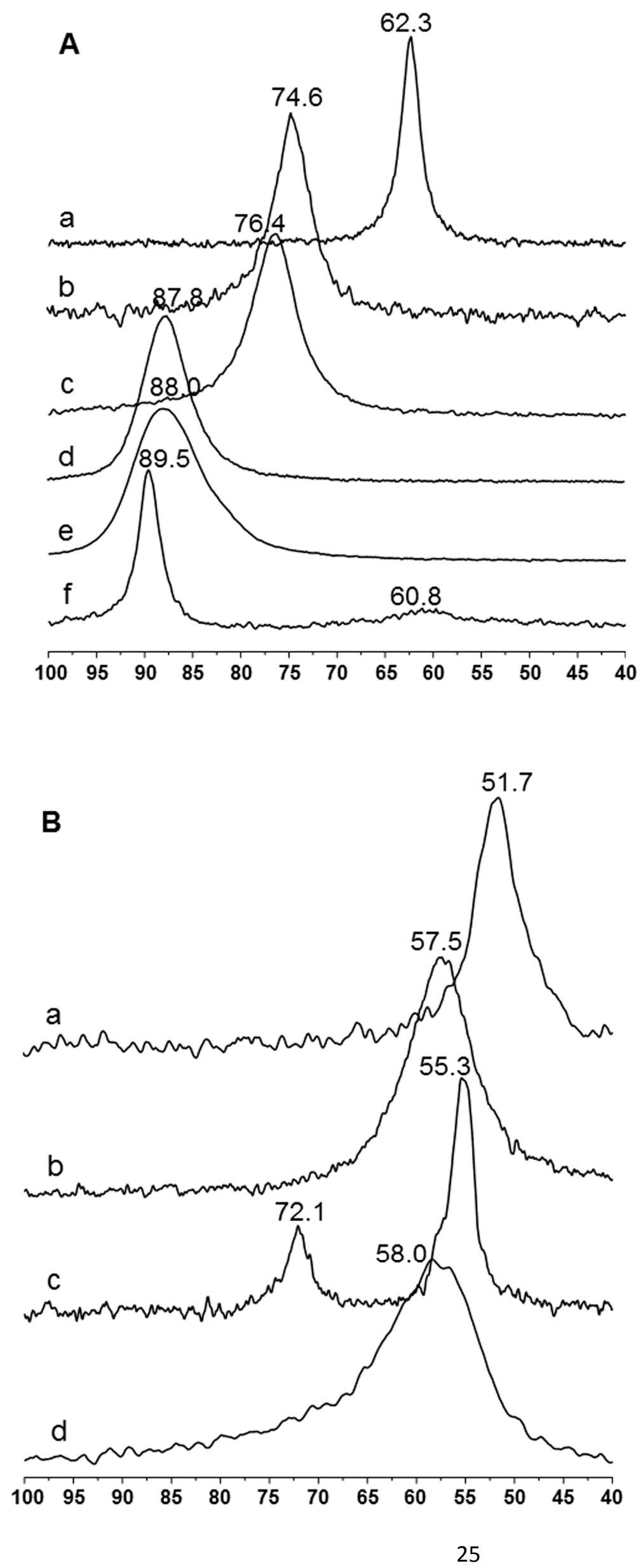


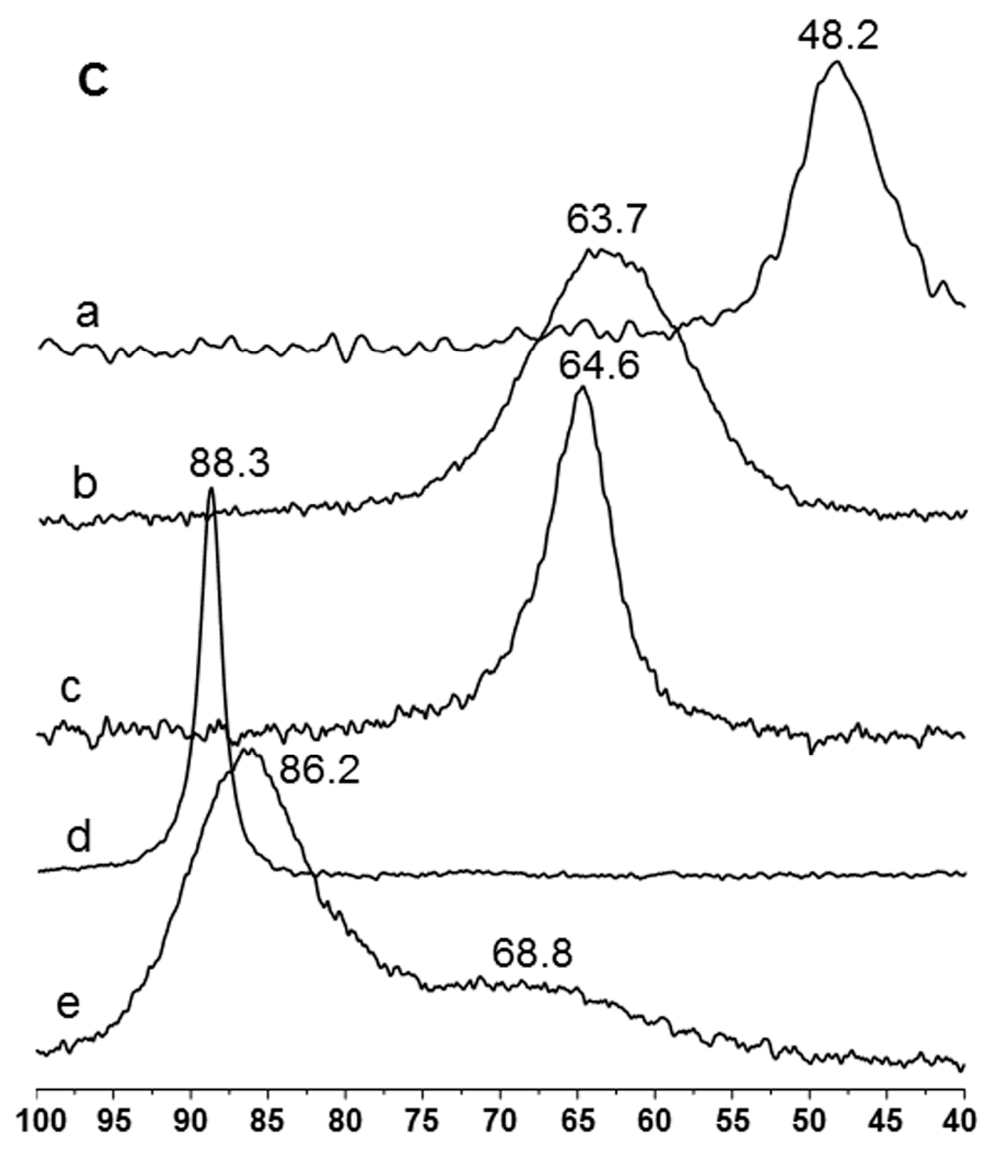

Figure 3. ${ }^{31} \mathrm{P}$ MAS NMR spectra of TEPO adsorbed on different solids. A) Adsorption from hexane/dichloromethane solution on: a) silica gel, b) PSS, c) DI9, d) D50, e) A15, f) SAC-13. B) Adsorption from dichloromethane solution on: a) SElor, b) HTC, c) CCR, d) SHTC. C) Adsorption from methanol solution on: a) SElor, b) HTC, c) CCR, d) D50, e) SHTC. 


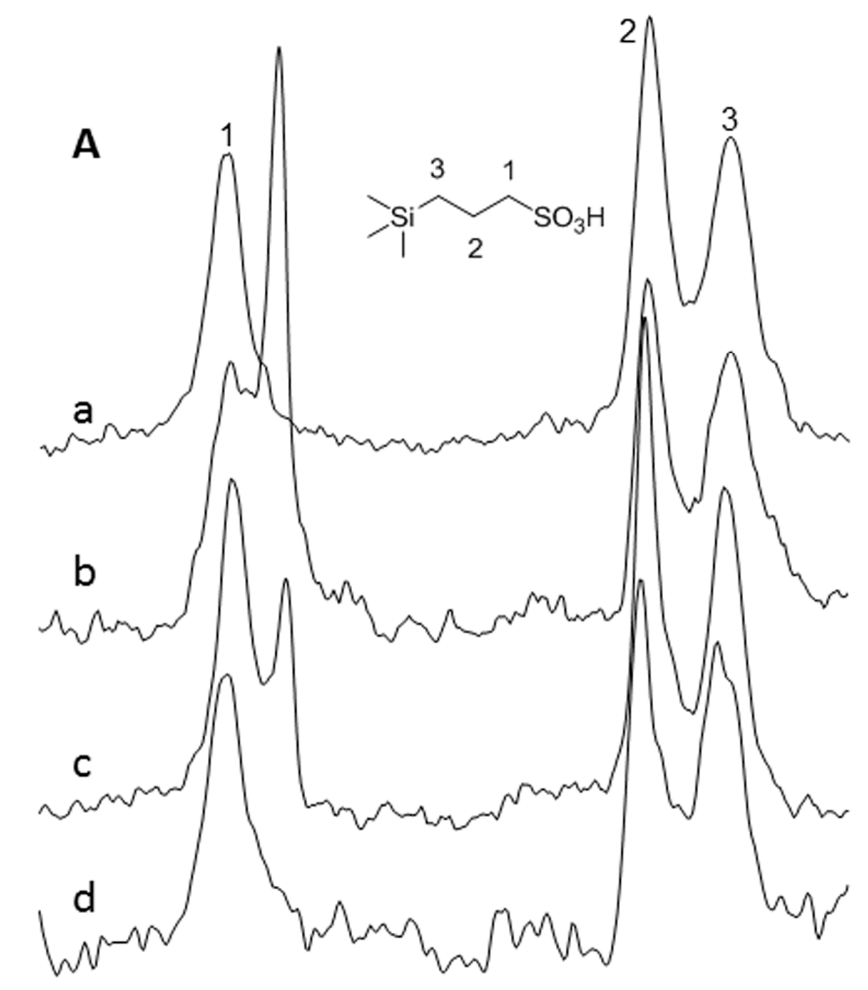

$\begin{array}{llllllllllllll}65 & 60 & 55 & 50 & 45 & 40 & 35 & 30 & 25 & 20 & 15 & 10 & 5 & 0\end{array}$
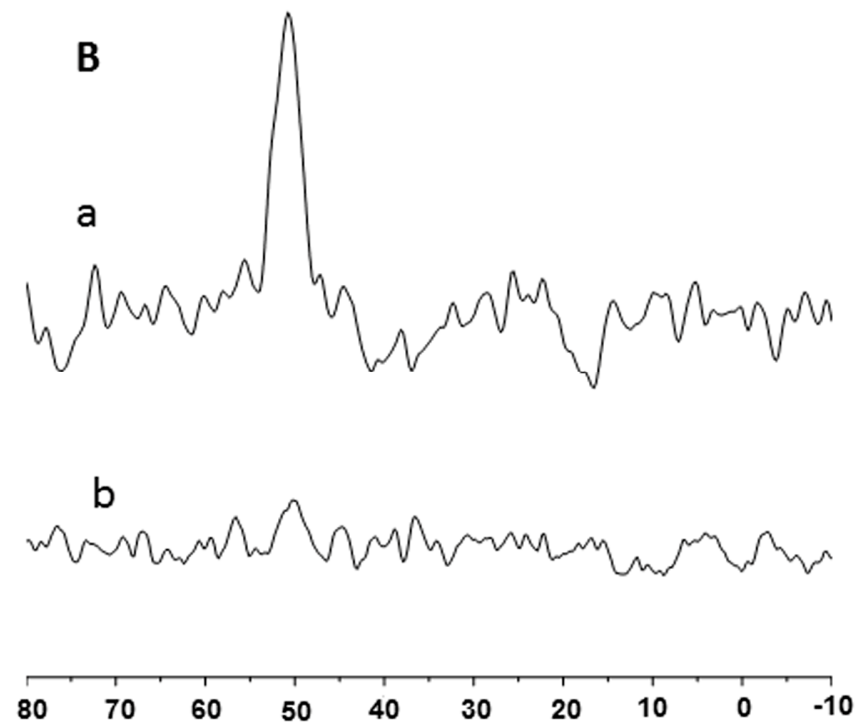

Figure $4 .{ }^{13} \mathrm{C}$ CP-MAS-NMR spectra. A) DI9: a) fresh catalyst, b) catalyst treated with methanol under reflux for $72 \mathrm{~h}, \mathrm{c}$ ) and d) catalyst treated with methanol and then under vacuum for increasing time periods. B) SAC-13: a) catalyst treated with methanol under reflux for $72 \mathrm{~h}, \mathrm{~b}$ ) catalyst treated with methanol and then under vacuum for $72 \mathrm{~h}$ (same number of scans). 


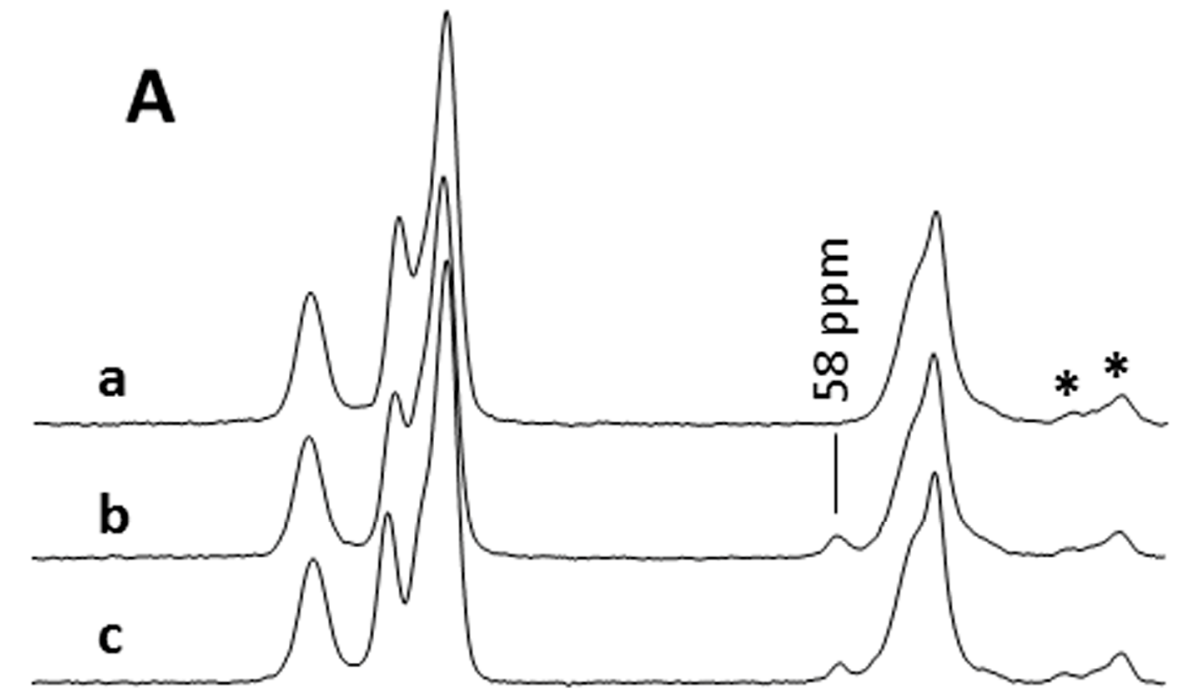

$\begin{array}{lllllllllllllllllllll}200 & 190 & 180 & 170 & 160 & 150 & 140 & 130 & 120 & 110 & 100 & 90 & 80 & 70 & 60 & 50 & 40 & 30 & 20 & 10 & 0\end{array}$

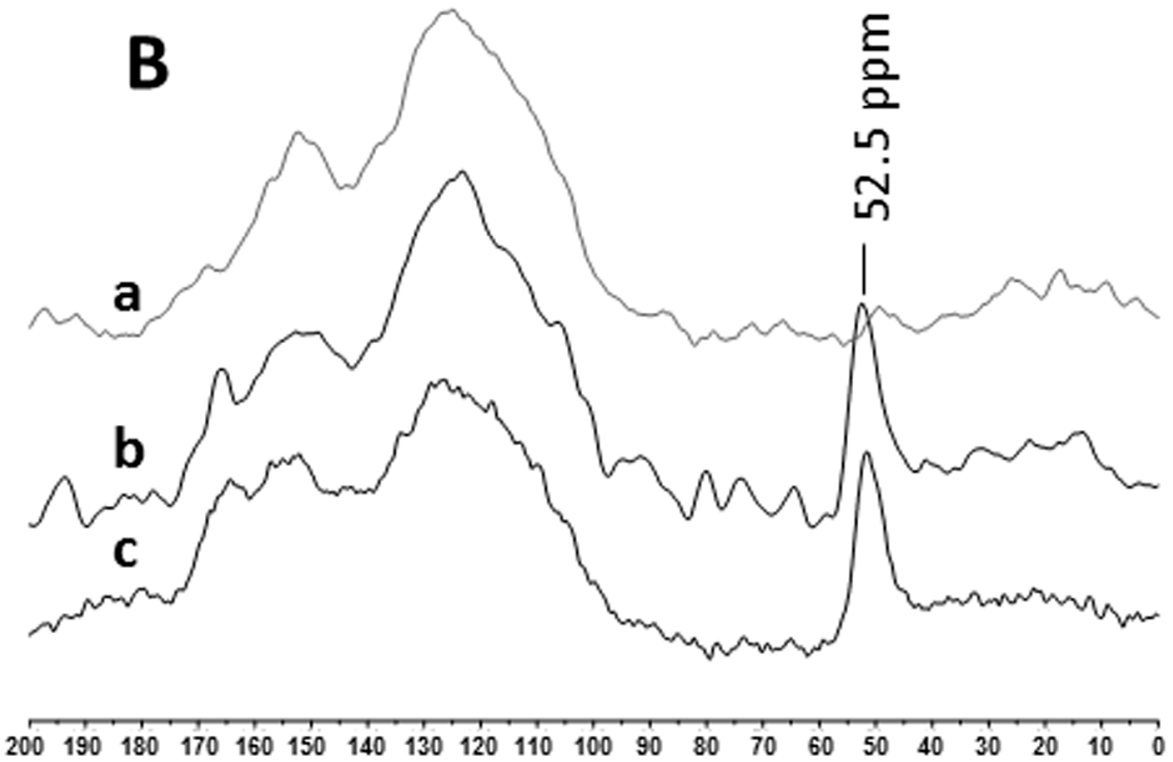

Figure $5 .{ }^{13}$ C CP-MAS-NMR spectra of: A) D50; B) SHTC. a) Fresh catalyst, b) catalyst treated with methanol under reflux for $72 \mathrm{~h}, \mathrm{c}$ ) catalyst treated with methanol and then under vacuum for $72 \mathrm{~h}$. (*) Spinning side bands. 

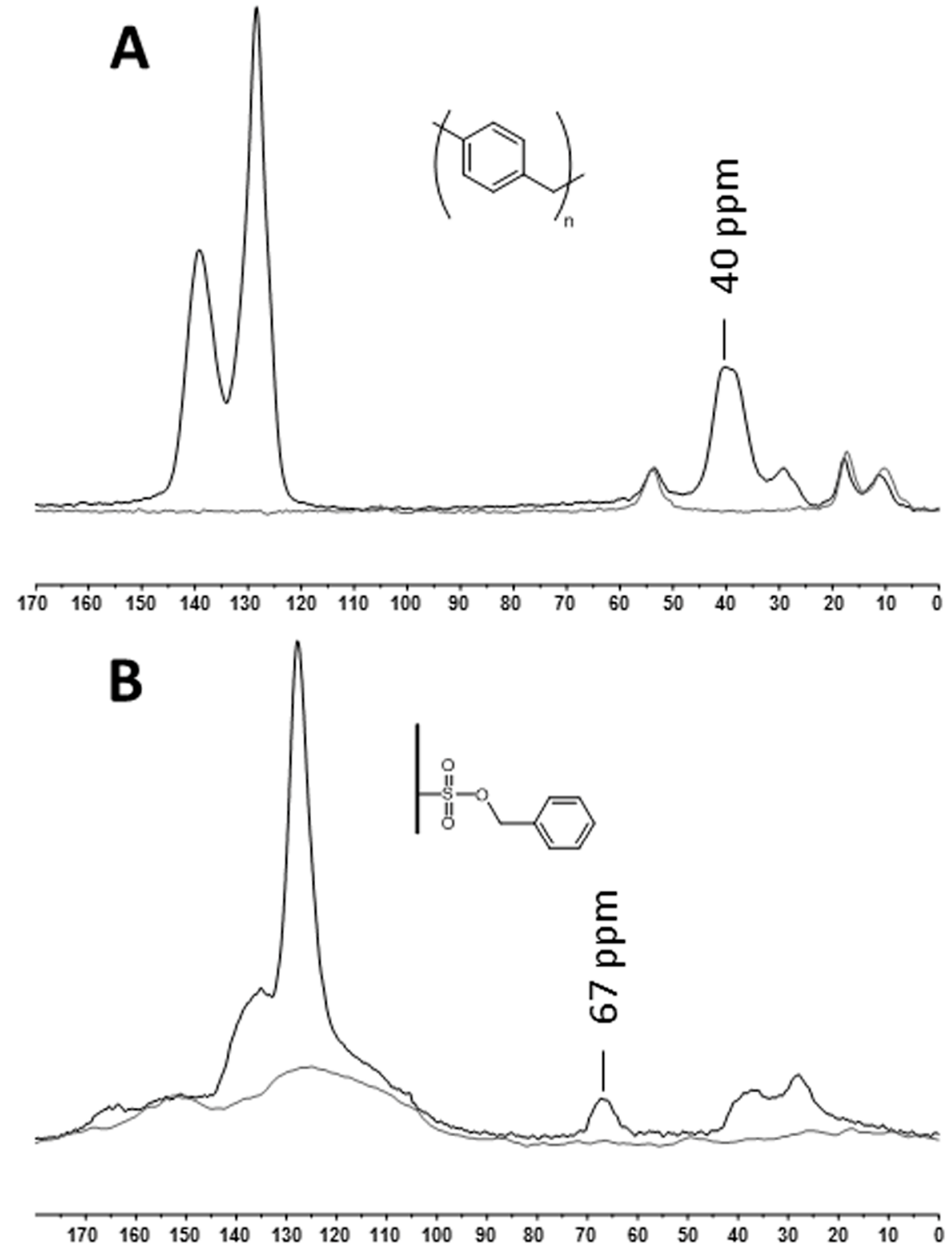

Figure $6 .{ }^{13} \mathrm{C}$ CP-MAS-NMR spectra of sulfonic solids treated with benzyl alcohol in toluene: A) DI9; B) SHTC. Grey lines correspond to the untreated solid. 


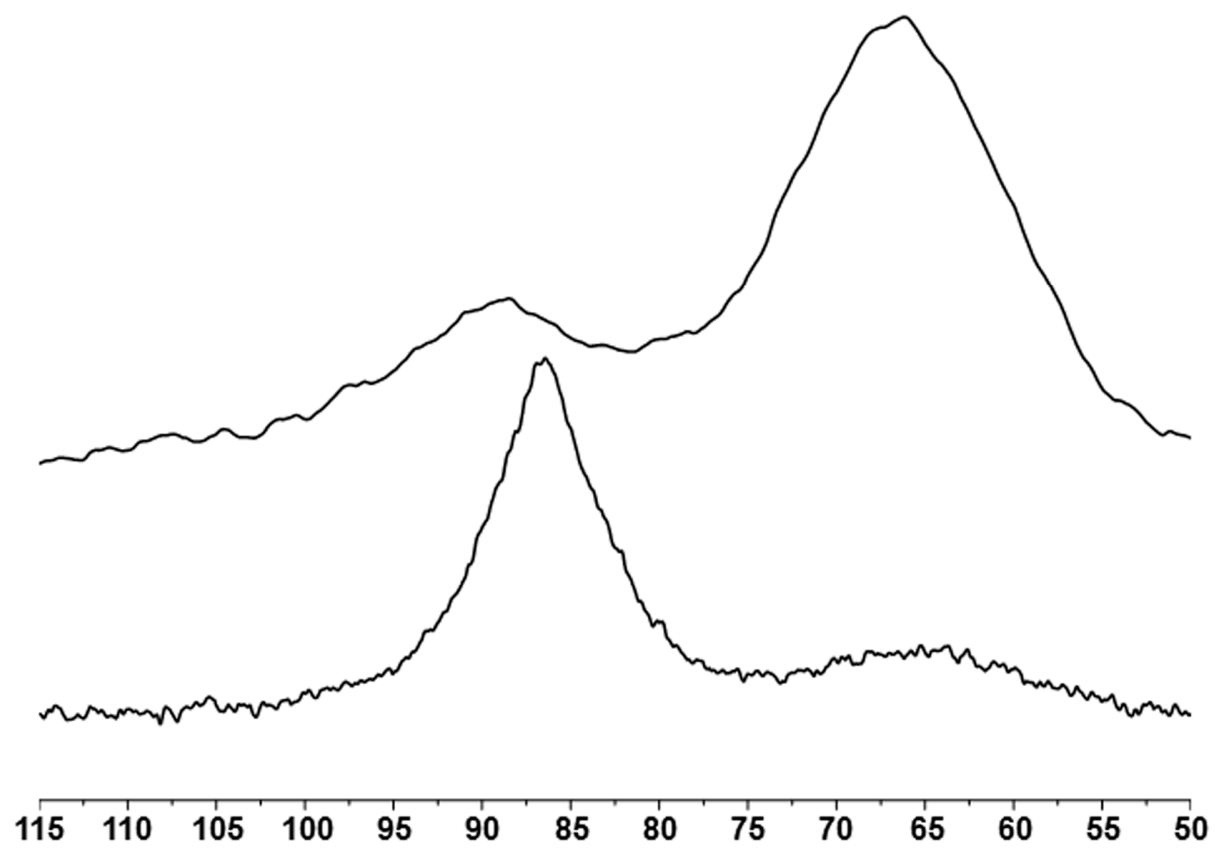

Figure $7 .{ }^{31} \mathrm{P}$ MAS NMR spectra of TEPO (0.8 eq) adsorbed from methanol solution on SHTC (bottom) and methanol-treated SHTC (top).

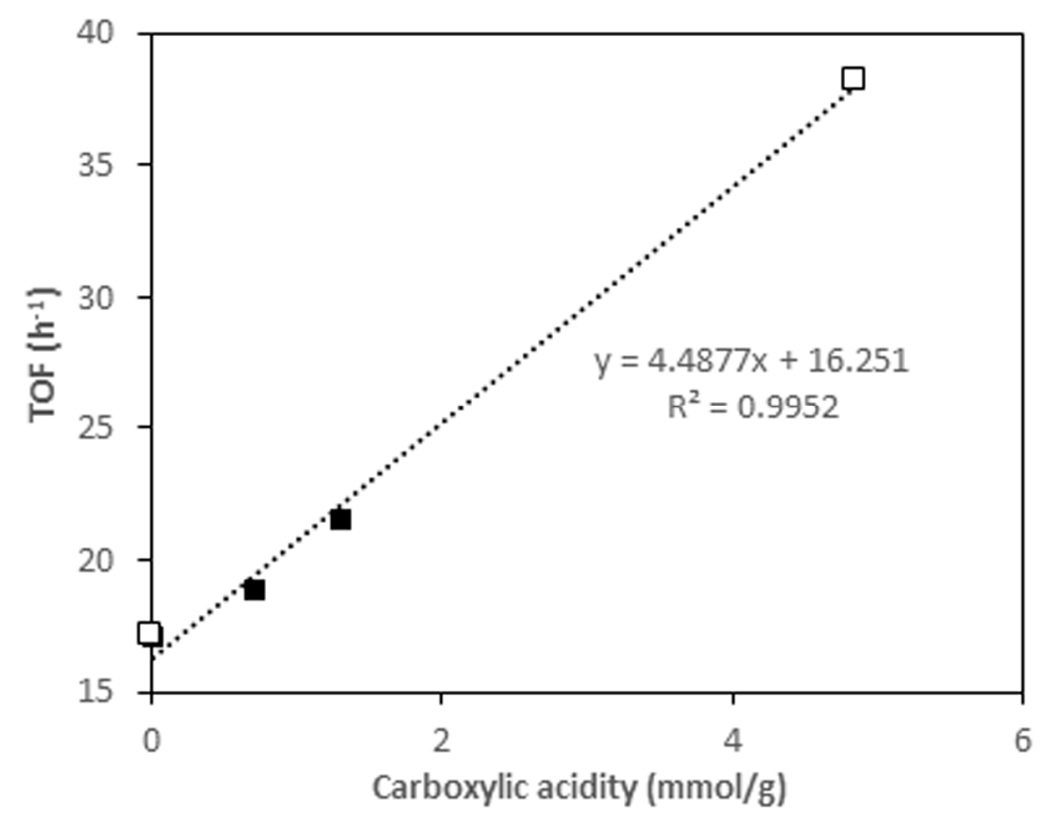

Figure 8. Correlation of the TOF $\left(\mathrm{h}^{-1}\right)$ in the esterification of fatty acids with ethanol vs content of carboxylic acids on the catalyst. Data: palmitic acid esterification (open symbols, this work) and oleic acid (filled symbols [19]). 

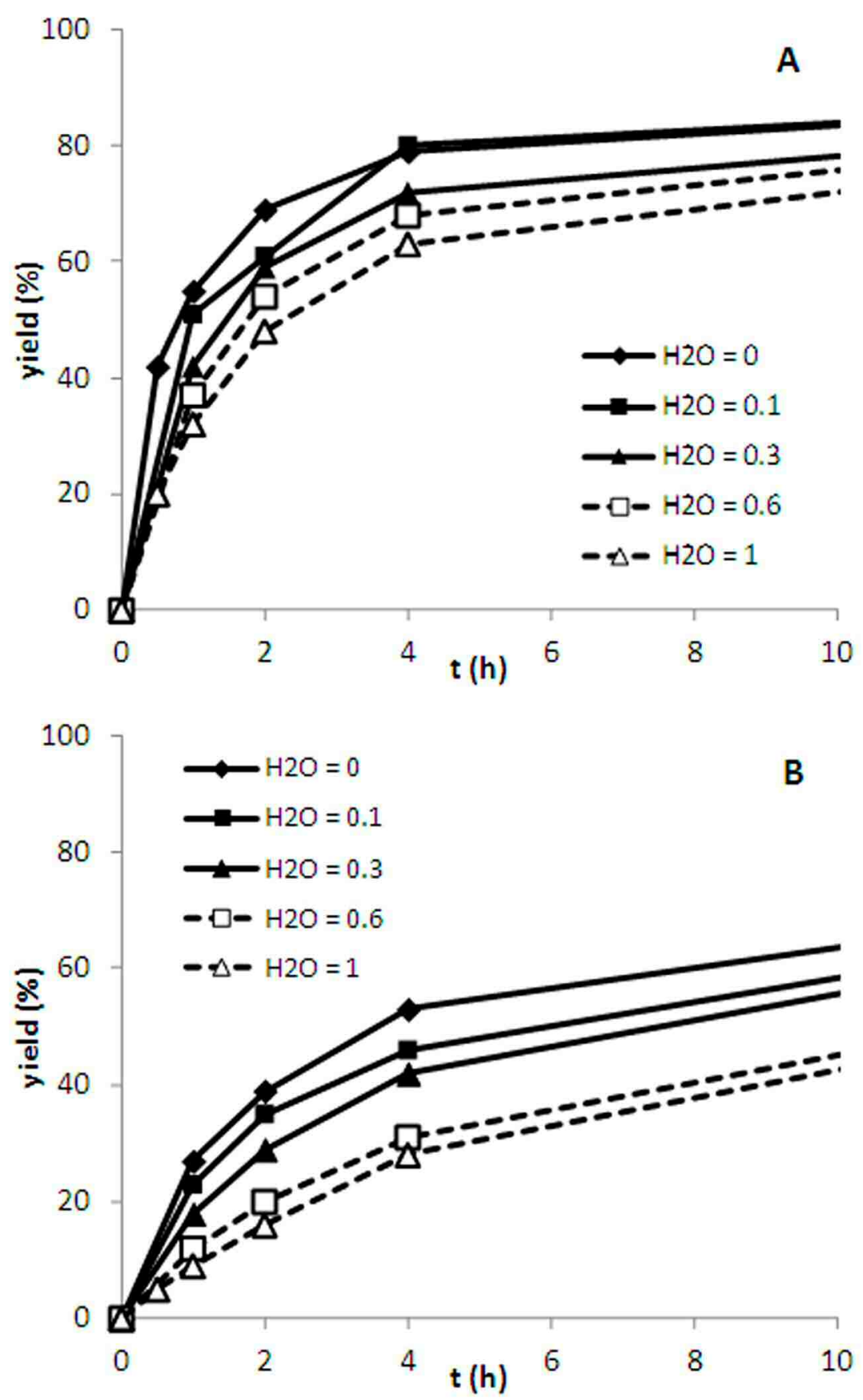

Figure 9. Water effect on esterification reaction: A) SHTC; B) DI9. The values in legends are water/palmitic acid molar ratios. 


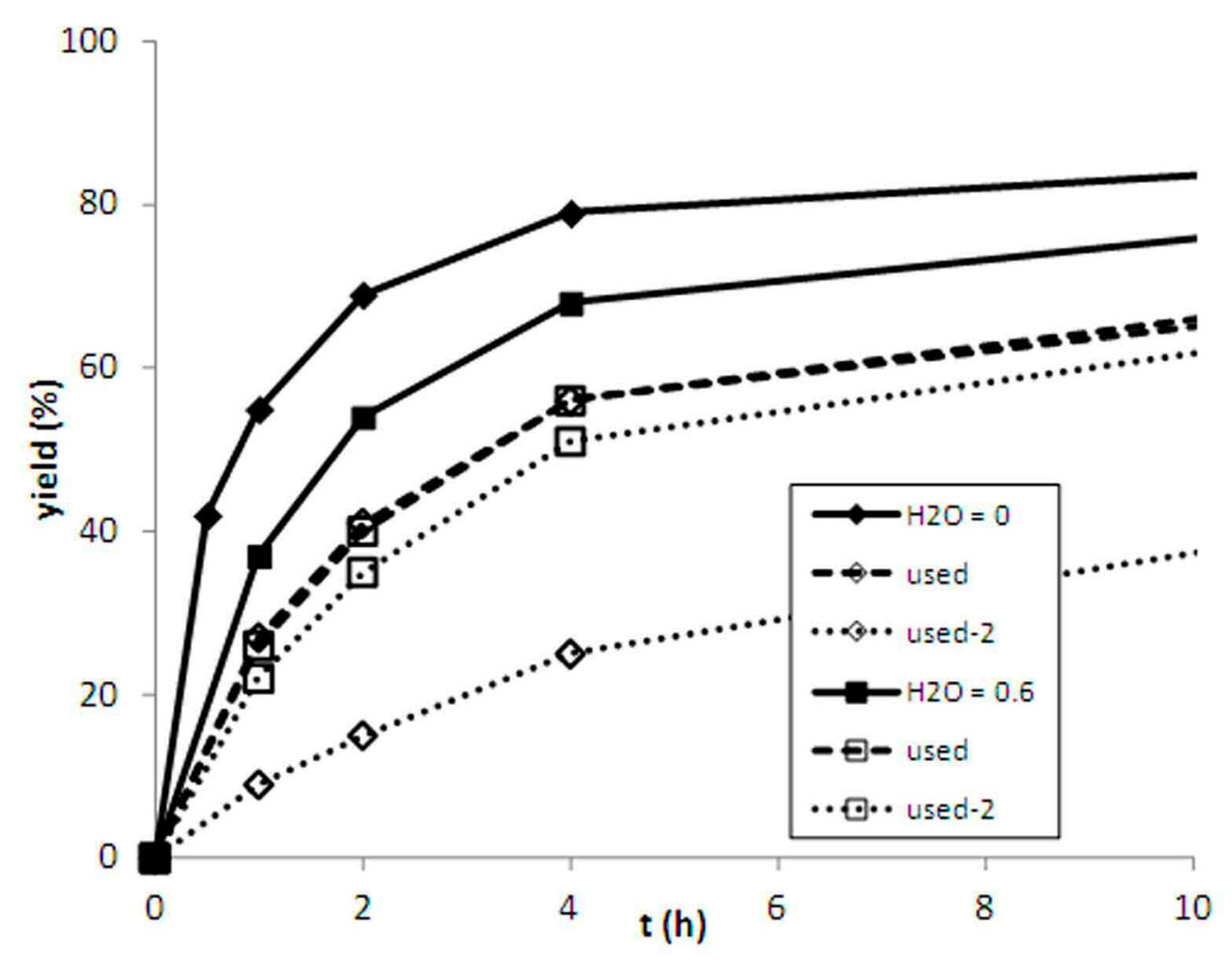

Figure 10. Water effect on recovery of SHTC. ( $\downarrow)$ Reactions in the absence of water. ( $\square$ ) Reactions with a water/palmitic acid molar ratio $=0.6$. Open symbols are the reuses of the catalyst under the same conditions: first reuse (dashed lines) and second reuse (dotted lines).

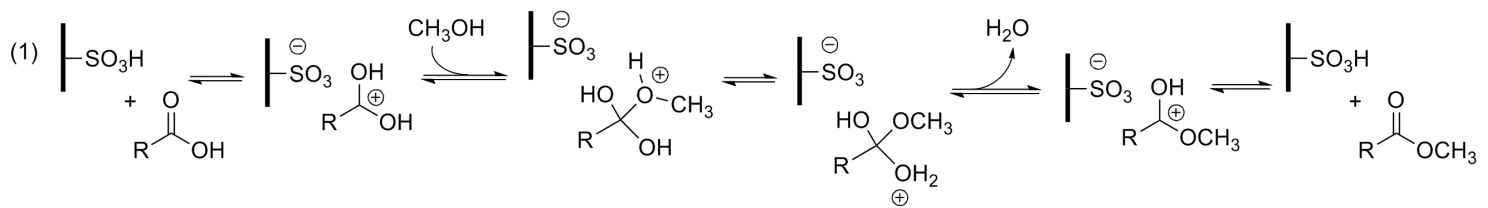

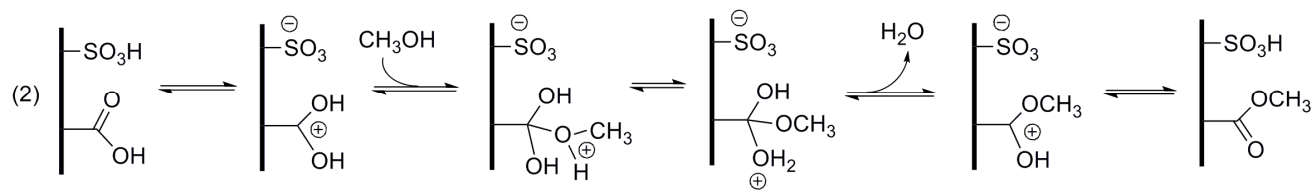

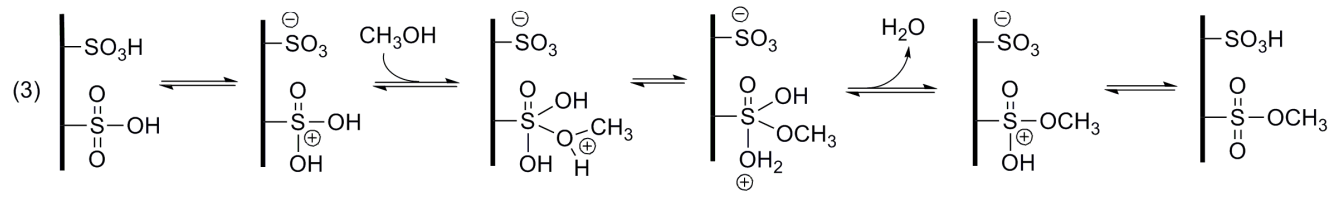

Scheme 1. Esterification mechanism (1) and proposed analogous mechanism for esterification of groups on solid surface (2 and 3). 